\title{
Effect of traumatic brain injury among U.S. servicemembers with
} amputation

\author{
Mitchell J. Rauh, PhD, PT, MPH; ${ }^{1-3^{*}}$ Hilary J. Aralis, MS; ${ }^{1}$ Ted Melcer, PhD; ${ }^{3}$ Caroline A. Macera, PhD; ${ }^{1,4}$ \\ Pinata Sessoms, PhD; ${ }^{1}$ Jamie Bartlett, PhD; $^{1}$ Michael R. Galarneau, $\mathbf{M S}^{\mathbf{3}}$ \\ ${ }^{1}$ Warfighter Performance Department, Naval Health Research Center, San Diego, CA; ${ }^{2}$ Doctor of Physical Therapy Pro- \\ gram, San Diego State University, San Diego, CA; ${ }^{3}$ Medical Modeling, Simulation and Mission Support Department, Naval \\ Health Research Center, San Diego, CA; ${ }^{4}$ Graduate School of Public Health, San Diego State University, San Diego, CA
}

\begin{abstract}
Servicemembers with combat-related limb loss often require substantial rehabilitative care. The prevalence of traumatic brain injury (TBI), which may impair cognitive and functional abilities, among servicemembers has increased. The primary objectives of this study were to determine the frequency of TBI among servicemembers with traumatic amputation and examine whether TBI status was associated with discharge to civilian status and medical and rehabilitative service use postamputation. U.S. servicemembers who had a combat-related amputation while deployed in Iraq or Afghanistan between 2001 and 2006 were followed for $2 \mathrm{yr}$ postamputation. Data collected includes injury mechanism; postinjury complications; Injury Severity Score (ISS); and follow-up data, including military service discharge status and number of medical, physical, occupational therapy, and prosthetic-related visits. Of the 546 servicemembers with combat-related amputations, 127 (23.3\%) had a TBI diagnosis. After adjusting for ISS and amputation location, those with TBI had a significantly greater mean number of medical and rehabilitative outpatient and inpatient visits combined $(p<0.01)$. Those with TBI were also at greater odds of developing certain postinjury complications. We recommend that providers treating servicemembers with limb loss should assess for TBI because those who sustained TBI required increased medical and rehabilitative care.
\end{abstract}

Key words: amputation, blasts, combat-related, military, occupational therapy, odds ratio, physical therapy, postinjury complications, prosthetic use, rehabilitative use, service discharge, traumatic brain injury.

\section{INTRODUCTION}

As of August 2008, approximately 31,000 U.S. servicemembers have been wounded in the conflicts related to Operation Iraqi Freedom (OIF) and Operation Enduring Freedom (OEF) [1]. Approximately 4 percent $(n=1,214)$ of the wounded servicemembers sustained an amputation, with 877 (72.2\%) experiencing a major limb amputation [1]. Because of technological advances in body armor, rapid evacuation, and early medical attention, the survival rate of servicemembers with combat-related amputation has increased [2]. Relative to previous conflicts, the amount of time and resources dedicated to the healthcare

Abbreviations: AIS = Abbreviated Injury Scale, CHAMPS = Career History Archival Medical and Personnel System, CI = confidence interval, DOD $=$ Department of Defense, DOF = degree of freedom, DVT = deep vein thrombosis, EMED = Expeditionary Medical Encounter Database, ICD-9 = International Classification of Diseases-9th Revision, IED = improvised explosive device, ISS = Injury Severity Score, OR = odds ratio, OEF = Operation Enduring Freedom, OIF = Operation Iraqi Freedom, $\mathrm{PE}=$ pulmonary embolism, TBI = traumatic brain injury.

*Address all correspondence to Mitchell J. Rauh, PhD, PT, MPH; Naval Health Research Center, Warfighter Performance Department, 140 Sylvester Rd, San Diego, CA 92106; 619-594-3706; fax: 619-767-0677.

Email: mrauh@mail.sdsu.edu

http://dx.doi.org/10.1682/JRRD.2011.11.0212 
of servicemembers with amputations has also significantly increased because of the relatively larger population of young servicemembers who require substantial care for complex physical and psychological issues [3-16]. Military rehabilitation programs for those with amputation address these unique issues and seek to improve outcomes by benefitting from the servicemembers' youth, fitness, and desire to return to an active lifestyle in conjunction with the availability of advanced prosthetic technologies, sports fitness techniques, and direct access to state-of-theart military healthcare [17-22].

In addition to the combat-related limb injury that necessitated an amputation, there is an increased likelihood that some servicemembers will also incur a traumatic brain injury (TBI) because of the nature of the blast weapons that caused the injury (e.g., conventional weapons [artillery, grenades, mortar, and small arms], improvised explosive devices [IEDs], mines, booby traps, and motor vehicle or aircraft accidents). According to the Department of Defense (DOD), as of July 2008, 8,089 servicemembers experienced a TBI that resulted from actions associated with OIF/OEF [23]. Of these, 5,792 (71.6\%) sustained TBI from a blast exposure. Consequences of TBI can be mild, moderate, or severe and can range from physical disability to long-term cognitive, behavioral, and social deficits. In a study of TBI among military personnel (primarily Marines) during the second phase of OIF, short-term follow-up of surviving patients with TBI indicated higher morbidity and medical use among the patients with more severe TBI, although mental health conditions were higher among patients with milder TBI [24].

Limb loss usually requires significant prosthetic and other functional rehabilitation training [25-26]. To our knowledge, only one study has examined the outcomes associated with long-term prosthetic use in patients with TBI and acquired limb loss. In a study of 12 civilian patients admitted with TBI and limb amputation, only 50 percent used a prosthesis and only 33 percent were considered able to use a prosthesis independently in the community [27]. Of the 10 patients with a lower-limb amputation, only 40 percent became ambulatory. Stone et al. suggested that diminished ability to use a prosthesis was related to ataxia; inability to withstand shear or loading on the residual limb; bilateral spasticity; contractures; underlying cognitive deficits, including perceptual dysfunction; or a combination of these [27].
The purpose of this study was to examine the effect of TBI on rehabilitative resource use and needs among servicemembers who received a combat-related major limb amputation as a result of a combat-related injury. Specifically, the objectives of this study were to (1) determine the frequency of TBI among servicemembers with traumatic limb amputation; (2) assess whether TBI status was associated with discharge to civilian status; and (3) examine the extent of medical, physical, and occupational therapy use during 2 yr postamputation.

\section{METHODS}

\section{Subjects}

The population for this study consisted of U.S. servicemembers who incurred a combat-related major limb amputation in OIF/OEF between 2001 and 2006. We defined a combat-related major limb amputation as an upper-limb, lower-limb, hand, or foot amputation (or in some instances, multiple amputations). We excluded servicemembers whose amputation involved only the finger(s) or toe(s).

\section{Identification of Subjects}

We identified servicemembers with a combat-related major limb amputation by searching the Expeditionary Medical Encounter Database (EMED), formerly known as the Navy-Marine Corps Combat Trauma Registry, and the Career History Archival Medical and Personnel System (CHAMPS). These databases contain standardized codes determined by medical providers and employers that are regularly updated [28-29]. We used the following codes to identify combat-related amputations in OIF/OEF:

- Major limb amputations (International Classification of Diseases-9th Revision [ICD-9] codes 887.0-887.7, 896.0-896.3, and 897.0-897.7).

- Injury cause codes indicating combat injury.

- Military treatment facility codes determining whether patients were treated at Landstuhl Regional Medical Center, Walter Reed Army Medical Center, or another military treatment facility.

\section{Expeditionary Medical Encounter Database}

The EMED is a triservice deployment health database consisting of medical encounter information that follows the medical chain of evacuation from point of injury through final outcome for U.S. servicemembers who get 
sick or are injured during deployment [28]. The EMED also allows identification and tracking of individuals through various levels of care and rehabilitation. This includes the capability of pulling cases within the database based on ICD-9 codes, Injury Severity Score (ISS), and Abbreviated Injury Scale (AIS) score, which are used specifically for identifying severity and anatomical location of injuries.

\section{Career History Archival Medical and Personnel System}

The CHAMPS database contains chronological entries of significant medical and personnel events for all armed services since 1999 [29]. Medical information in CHAMPS is routinely updated using both Active Duty medical databases and records from private healthcare facilities that are reimbursed for services provided to military personnel. The CHAMPS has critical fields that might be indicators of individuals with amputations, including ICD-9 and Current Procedural Terminology-4th Edition codes.

\section{Traumatic Brain Injury Status}

We followed servicemembers with combat-related major limb amputations who did and did not receive a TBI diagnosis for 24 mo postamputation. We identified all TBI cases from the CHAMPS and EMED. Based on the expanded Barell injury diagnosis matrix [30], an ICD-9 diagnosis code in any of the following ranges was defined as a TBI [30-31]: 310.2 (postconcussion syndrome), 800.0-801.9 (fractures of the vault or base of the skull), 803.0-804.9 (other and unqualified and multiple fractures of the skull), 850.0-854.1 (intracranial injury, including concussion, contusion, laceration, and hemorrhage), and 959.01 (unspecified head injury) with additional verification. Patients often had multiple ICD-9 codes; therefore, any code falling within the TBI case definition qualified them for inclusion. We did not consider individuals diagnosed with one of these ICD-9 codes $\geq 90$ d postinjury a TBI case because current evidence suggests that there are no mild TBI-attributable, objectively measured cognitive deficits beyond 1 to 3 mo postinjury [32].

\section{Other Injuries and Injury Severity}

We extracted other injuries incurred during the event that caused the amputation from the EMED and CHAMPS databases. Trained EMED staff described the severity of patient injuries using two standardized mea- sures of injury classification and severity assigned. These measures included AIS scores (injury-specific scores based on an anatomical description of the injury, with scores ranging from 1 [relatively minor] to 6 [currently untreatable]) [32] and ISS (overall measure of severity with scores ranging from 0 to 75 derived from AIS scores in six body regions: head, face, chest, abdomen, limbs, and external soft tissue) [32]. The three most severe injuries of the six body regions are selected for determining an individual's ISS.

\section{Other Descriptive Data}

We also extracted the following descriptive variables from CHAMPS: sex, age $(<25,25-29$, and $\geq 30$ years), service branch (Army, Air Force, Marine Corps, and Navy), service grade (junior enlisted [E1-E4], senior enlisted [E5-E9], and warrant officer/officer), and service component (regular, reserve, and National Guard).

\section{Follow-Up Data}

We searched the CHAMPS database to assess the relatively short-term personnel-related and medical outcomes. Variables extracted or computed from CHAMPS data included postamputation attrition information, including reason for discharge to civilian status; postinjury medical complications, including number and type of diagnosis; inpatient hospitalization variables, including number and date of admissions; and outpatient visit characteristics, including number and date of visits. Outcome data included physical therapy, occupational therapy, and prostheticrelated visits over the course of the 2 yr follow-up and reasons for service discharge to civilian status.

\section{Data Analysis}

We calculated chi-square tests to determine associations between TBI status and study sample demographics such as sex, age, service branch, service grade, service component, anatomical location of amputation (upper limb: transhumeral, transradial, bilateral, unrecorded, and lower limb: transfemoral, transtibial, bilateral, unrecorded), postinjury complications, overall ISS (1-15 and $\geq 16$ ) [33], and number of other injuries at time of amputation (0, 1-4, 5-9, and $\geq 10$ ). We also calculated the chi-square test to determine the association between mechanism of injury and TBI status. We used a $t$-test to compare the mean time from injury with amputation event by TBI status.

We calculated adjusted odds ratios (ORs) and 95 percent confidence intervals (CIs) using multiple logistic 
regression for postinjury complications, comparing the odds of each complication among servicemembers with a TBI with the odds of complication among injured servicemembers without a TBI, adjusting for ISS and amputation location (upper limb, lower limb, or both limbs).

We constructed Poisson regression models for count data (adjusting for ISS and amputation location) to determine mean differences in number of physical therapy, occupational therapy, and total medical visits during the entire $2 \mathrm{yr}$ follow-up and per quarter of follow-up for servicemembers with and without TBI. We generated adjusted mean counts (number of visits) for servicemembers with and without a recorded TBI based on parameter estimates from these Poisson regression models and assessed significant differences. Additionally, we constructed a Cox proportional hazards model to examine the number of days between the amputation event and discharge from service and to compare the risk of discharge among servicemembers with and without a recorded TBI (while adjusting for ISS and amputation location). The Cox proportional hazards model considered servicemembers who were not discharged during the $2 \mathrm{yr}$ follow-up as censored observations, with censoring dates equal to $2 \mathrm{yr}$ postamputation, and we used a 1-degree of freedom (DOF) Wald chi-square test to assess the relationship between TBI status and survival. We used SAS version 9.2 statistical software (SAS Inc; Cary, North Carolina) for all analyses.

\section{RESULTS}

\section{Final Sample}

Of the 546 servicemembers identified with a combatrelated major limb amputation, 127 (23.3\%) had a TBI diagnosis. We found no significant differences between servicemembers with and without TBI with respect to sex $\left(\chi^{2}=1.26, p=0.26\right)$, age $\left(\chi^{2}=1.77, p=0.41\right)$, service branch $\left(\chi^{2}=0.21, p=0.98\right)$, service component $\left(\chi^{2}=\right.$ 2.79, $p=0.25)$, and service grade $\left(\chi^{2}=2.33, p=0.31\right)$ (Table 1).

Of those with TBI, 51 percent $(n=65)$ were diagnosed on the first day of injury. By $30 \mathrm{~d}$ postinjury, 89.0 percent had been diagnosed with TBI. Overall, 74.7 percent of the servicemembers had their limb amputated within $1 \mathrm{~d}$ of the injury, and this rate was similar for those with TBI (79.5\%) and without TBI (73.3\%) $\left(\chi^{2}=2.02\right.$, $p=0.16)$.
Table 1.

Demographic characteristics of servicemembers by traumatic brain injury (TBI) status in Operation Iraqi Freedom/Operation Enduring Freedom, 2001-2006 $(n=546)$.

\begin{tabular}{|c|c|c|c|}
\hline Demographic & $\begin{array}{c}\text { TBI } \\
(n=127) \\
n(\%)\end{array}$ & $\begin{array}{c}\text { No TBI } \\
(n=419) \\
n(\%)\end{array}$ & $p$-Value ${ }^{*}$ \\
\hline$\overline{\text { Sex }}$ & & & 0.26 \\
\hline Male & $126(23.6)$ & 409 (76.4) & \\
\hline Female & $1(9.1)$ & 10 (90.9) & \\
\hline Age (yr) & & & 0.41 \\
\hline$<25$ & $77(25.2)$ & $228(74.8)$ & \\
\hline $25-29$ & $29(22.0)$ & $103(78.0)$ & \\
\hline$\geq 30$ & $21(19.3)$ & $88(80.7)$ & \\
\hline Branch of Service & & & 0.98 \\
\hline Army & $88(22.8)$ & $298(77.2)$ & \\
\hline Air Force & $2(25.0)$ & $6(75.0)$ & \\
\hline Marine Corps & $32(24.1)$ & $101(75.9)$ & \\
\hline Navy & $5(26.3)$ & $14(73.7)$ & \\
\hline Service Component & & & 0.25 \\
\hline Regular & $107(24.6)$ & $328(75.4)$ & \\
\hline Reserve & $14(20.6)$ & $54(79.4)$ & \\
\hline National Guard & $6(13.9)$ & 37 (86.1) & \\
\hline Service Grade & & & 0.31 \\
\hline Junior Enlisted (E1-E4) & $77(25.2)$ & $229(74.8)$ & \\
\hline Senior Enlisted (E5-E9) & $44(22.0)$ & $156(78.0)$ & \\
\hline Officer/Warrant Officer & $6(15.0)$ & $34(85.0)$ & \\
\hline
\end{tabular}

\section{Mechanism of Injury}

Overall, 87.4 percent of the injuries that resulted in a limb amputation were caused by a blast injury. A total of 342 injuries (62.6\%) resulted in a limb amputation caused by a mine explosion, which was more common among servicemembers who received a lower-limb amputation than among servicemembers with an amputation in a different body region $\left(\chi^{2}=19.74, p<0.0001\right)$. Mine explosions were also a larger cause of injury among servicemembers who incurred a TBI (74.0\%) than among those who were not diagnosed with TBI (59.2\%) $\left(\chi^{2}=\right.$ 9.16, $p=0.002$ ).

\section{Anatomical Location of Amputation by Traumatic Brain Injury Status}

A diagnosis of TBI was not significantly associated with lower-, upper-, or bilateral-limb amputation $\left(\chi^{2}=\right.$ 0.98, $p=0.61)$ (Table 2). Overall, most $(76.7 \%, n=419)$ amputations were of the lower limb only. Of the servicemembers with a lower-limb amputation only, those with TBI were significantly more likely to have a bilateral 
Table 2.

Anatomical location of amputation for servicemembers by traumatic brain injury (TBI) status in Operation Iraqi Freedom/Operation Enduring Freedom, 2001-2006 $(n=546)$.

\begin{tabular}{lccc}
\hline \multicolumn{1}{c}{ Amputation } & $\begin{array}{c}\text { TBI } \\
(\boldsymbol{n}=\mathbf{1 2 7}), \\
\boldsymbol{n ( \% )}\end{array}$ & $\begin{array}{c}\text { No TBI } \\
(\boldsymbol{n}=\mathbf{4 1 9 )} \\
\boldsymbol{n} \mathbf{( \% )}\end{array}$ & $\boldsymbol{p}$-Value* \\
\hline Upper Limb & 27 & 85 & 0.47 \\
Transhumeral & $12(44.4)$ & $31(36.5)$ & \\
Transradial & $12(44.4)$ & $46(54.1)$ & \\
Bilateral & $1(3.7)$ & $6(7.1)$ & \\
Unrecorded & $2(7.4)$ & $2(2.4)$ & \\
Lower Limb & 95 & 324 & 0.002 \\
Transfemoral & $31(32.6)$ & $95(29.3)$ & \\
Transtibial & $33(34.7)$ & $172(53.1)$ & \\
Bilateral & $31(32.6)$ & $54(16.7)$ & \\
Unrecorded & $0(0.0)$ & $3(0.9)$ & \\
Upper and Lower Limb & 5 & 10 & \\
*Chi-square test for upper limb, lower limb, or both $(p=0.61)$. & \\
\hline
\end{tabular}

lower-limb or a unilateral transfemoral amputation and less likely to have a transtibial amputation than servicemembers who did not sustain a TBI $\left(\chi^{2}=16.19, p=0.002\right)$. However, TBI was not significantly associated with the level of upper-limb amputation $\left(\chi^{2}=2.54, p=0.47\right)$.

\section{Injury Severity and Number of Other Injuries}

Servicemembers with TBI were significantly more likely to have an ISS of $\geq 16$ (66.9\%) than servicemembers without TBI $(39.1 \%)\left(\chi^{2}=30.34, p<0.0001\right)$ (Table 3). Compared with servicemembers without TBI, those with a recorded TBI had a significantly greater number of other injuries occurring at the same time as the amputation event $\left(\chi^{2}=39.05, p<0.0001\right)$.

\section{Traumatic Brain Injury and Discharge to Civilian Status}

Of the 546 servicemembers who had a combat-related major limb amputation, 324 (59.3\%) were discharged from military service during the $2 \mathrm{yr}$ follow-up period. Of the servicemembers discharged from military service, 71 (21.9\%) had a recorded TBI; this percentage was not significantly different from the percentage who reported a TBI among those who did not discharge in the $2 \mathrm{yr}$ followup period $(25.2 \%)\left(\chi^{2}=0.81, p=0.37\right)$. Using a Wald chisquare test conducted in association with the Cox proportional hazards model controlling for ISS and amputation location, we concluded that time between amputation and discharge did not differ significantly between servicemembers with and without a recorded TBI (Wald 1-DOF $\chi^{2}=$ $2.53, p=0.11)$. Approximately 63 percent $(n=203)$ of dis-
Table 3.

Other injuries and overall injury severity for servicemembers by traumatic brain injury (TBI) status in Operation Iraqi Freedom/ Operation Enduring Freedom, 2001-2006 ( $n=546)$.

\begin{tabular}{|c|c|c|c|}
\hline Variable & $\begin{array}{c}\text { TBI } \\
(n=127), \\
n(\%)\end{array}$ & $\begin{array}{c}\text { No TBI } \\
(n=419) \\
n(\%)\end{array}$ & $p$-Value ${ }^{*}$ \\
\hline Injury Severity Score & & & $<0.0001$ \\
\hline $1-15$ & $42(33.1)$ & $255(60.9)$ & \\
\hline$\geq 16$ & 85 (66.9) & $164(39.1)$ & \\
\hline No. of Other Injuries ${ }^{\dagger}$ & & & $<0.0001$ \\
\hline 0 & $4(3.2)$ & $44(10.5)$ & \\
\hline $1-4$ & 49 (38.6) & $241(57.5)$ & \\
\hline $5-9$ & $63(49.6)$ & $128(30.6)$ & \\
\hline$\geq 10$ & $11(8.7)$ & $6(1.4)$ & \\
\hline
\end{tabular}

${ }^{*}$ Chi-square test.

${ }^{\dagger}$ Injuries other than injury that resulted in amputation.

charged servicemembers retired with permanent disability, a finding that was similar for those who incurred or did not incur TBI. Of the servicemembers with a recorded TBI, 34 percent retired with temporary disability. Only 20 percent of servicemembers without a recorded TBI retired with temporary disability. A smaller percentage of those with TBI retired from service for one of a variety of different reasons not related to disability.

Of the 222 servicemembers not discharged from military service, a higher percentage were older $\left(\chi^{2}=28.06\right.$, $p<0.0001)$, regular service component $\left(\chi^{2}=54.93, p<\right.$ $0.0001)$, and of senior enlisted or officer status $\left(\chi^{2}=19.80\right.$, $p<0.0001$ ) (Table 4). We found no other significant differences between servicemembers who discharged or did not discharge from military service.

\section{Medical and Rehabilitative Visits by Traumatic Brain Injury Status}

Among the 222 servicemembers who remained in the military (i.e., not discharged) and were followed for $2 \mathrm{yr}$, those with a recorded TBI had a significantly greater mean number of medical and rehabilitative outpatient and inpatient visits combined than servicemembers who did not sustain TBI after adjusting for ISS and amputation location (Wald $\chi^{2}=2,120.61, p<0.01$ ) (Table 5). Additionally, subjects with a recorded TBI had a greater mean number of visits to physical therapy (Wald $\chi^{2}=$ 143.82, $p<0.01$ ) and occupational therapy (Wald $\chi^{2}=$ 48.95, $p<0.01$ ) outpatient clinics, after adjusting for ISS and amputation location using a Poisson regression model. 
Table 4.

Comparison of demographic characteristics among servicemembers who did and did not complete 2 yr follow-up $(n=546)$.

\begin{tabular}{lccc}
\hline \multicolumn{1}{c}{ Demographic } & $\begin{array}{c}\text { Follow-up } \\
(\boldsymbol{n}=\mathbf{2 2 2}),\end{array}$ & $\begin{array}{c}\text { No Follow-up } \\
(\boldsymbol{n}=\mathbf{3 2 4}),\end{array}$ & $\boldsymbol{p}$-Value* \\
& $56(\mathbf{n})$ & $\mathbf{n ( \% )}$ & \\
\hline TBI & & $71(21.9)$ & 0.37 \\
Sex & $218(98.2)$ & $317(97.8)$ & 0.77 \\
$\quad$ Male & $4(1.8)$ & $7(2.2)$ & \\
Female & & & $<0.0001$ \\
Age (yr) & $95(42.8)$ & $210(64.8)$ & \\
$\quad<25$ & $64(28.8)$ & $68(21.0)$ & \\
25-29 & $63(28.4)$ & $46(14.2)$ & \\
$\geq 30$ & & & 0.48 \\
Branch of Service & $151(68.0)$ & $235(72.5)$ & \\
Army & $5(2.3)$ & $3(0.9)$ & \\
Air Force & $58(26.1)$ & $75(23.2)$ & \\
Marine Corps & $8(3.6)$ & $11(3.4)$ & \\
Navy & & & $<0.0001$ \\
Service Component & $145(65.3)$ & $290(89.5)$ & \\
Regular & $54(24.3)$ & $14(4.3)$ & \\
Reserve & $23(10.4)$ & $20(6.2)$ & \\
$\quad$ National Guard & & & $<0.0001$ \\
Military Rank & $101(45.5)$ & $205(63.3)$ & \\
Junior Enlisted (E1-E4) & $96(43.2)$ & $104(32.1)$ & \\
Senior Enlisted (E5-E9) & $25(11.3)$ & $15(4.6)$ & \\
Officer/Warrant Officer & & & \\
*Chi-square test. & & & \\
TBI = traumatic brain injury. & & & \\
\hline \hline
\end{tabular}

While the adjusted mean number of physical therapy outpatient visits per quarter following amputation was similar for servicemembers who incurred or did not incur a TBI, the adjusted mean number of physical therapy outpatient visits was significantly higher among servicemembers with TBI during quarter 6 (Wald $\chi^{2}=83.09, p<$ 0.01) (Figure). While the adjusted mean number of occupational therapy outpatient visits per quarter following amputation was consistently higher throughout most of the 2 yr follow-up period for servicemembers with TBI, it was significantly higher during quarters 1 (Wald $\chi^{2}=$ 5.22, $p=0.02$ ), 2 (Wald $\chi^{2}=8.39, p<0.01$ ), 5 (Wald $\chi^{2}=$ 13.76, $p<0.01$ ), and 6 (Wald $\chi^{2}=37.55, p<0.01$ ). The adjusted mean number of prosthetic training visits was variable over time for servicemembers with or without TBI. While those with TBI averaged fewer visits per quarter during the first two quarters than those without TBI (Wald $\chi^{2}=32.43, p<0.01$; and Wald $\chi^{2}=20.77, p<$ 0.01 ), those with TBI averaged more visits during quarter 4 (Wald $\chi^{2}=5.86, p=0.02$ ). In the final two quarters, none of the remaining servicemembers who sustained a TBI continued to require prosthetic training. Additionally, in the second to last quarter, none of the servicemembers without a TBI were seen for prosthetics training.

\section{Postinjury Complications by Traumatic Brain Injury Status}

The most common postinjury complications for all servicemembers who incurred an amputation were phantom limb syndrome $(n=126,56.8 \%)$, anemia ( $n=108$, 48.7\%), and bacterial infections ( $n=83,37.4 \%$ ) (Table 6). Compared with servicemembers without TBI, servicemembers with TBI had significantly more postinjury complications. Of servicemembers who incurred a TBI, over one-third $(41.1 \%)$ had five or more additional complications beyond their amputation and TBI injury $\left(\chi^{2}=8.67\right.$, $p=0.003$ ). Servicemembers with TBI were significantly more likely to have developed an infection and/or inflammation due to a device $\left(\chi^{2}=12.42, p=0.0004\right)$, pneumonia $\left(\chi^{2}=6.80, p=0.0004\right)$, deep vein thrombosis (DVT) and/or pulmonary embolism (PE) $\left(\chi^{2}=10.11, p=0.002\right)$, anemia $\left(\chi^{2}=5.75, p=0.02\right)$, septicemia $\left(\chi^{2}=5.30, p=\right.$ $0.02)$, or heterotopic ossification $\left(\chi^{2}=5.02, p=0.03\right)$ than servicemembers without TBI (Table 6).

Table 5.

Unadjusted and adjusted mean number of medical and rehabilitative care visits by traumatic brain injury (TBI) status during 2 yr follow-up period in Operation Iraqi Freedom/Operation Enduring Freedom, 2001-2006 $(n=222)$.

\begin{tabular}{|c|c|c|c|}
\hline No. of Visits & TBI $(n=56)$ & No TBI $(n=166)$ & p-Value \\
\hline \multicolumn{4}{|c|}{ Total Medical and Rehabilitation Inpatient and Outpatient } \\
\hline Adjusted Mean & 476.2 & 337.5 & $<0.01^{*}$ \\
\hline Mean \pm SD & $102.7 \pm 101.8$ & $81.3 \pm 67.0$ & $<0.01$ \\
\hline Adjusted Mean & 92.2 & 75.2 & $<0.01^{*}$ \\
\hline \multicolumn{4}{|l|}{ Occupational Therapy Outpatient } \\
\hline Adjusted Mean & 17.8 & 12.9 & $<0.01^{*}$ \\
\hline
\end{tabular}


(a)



(b)

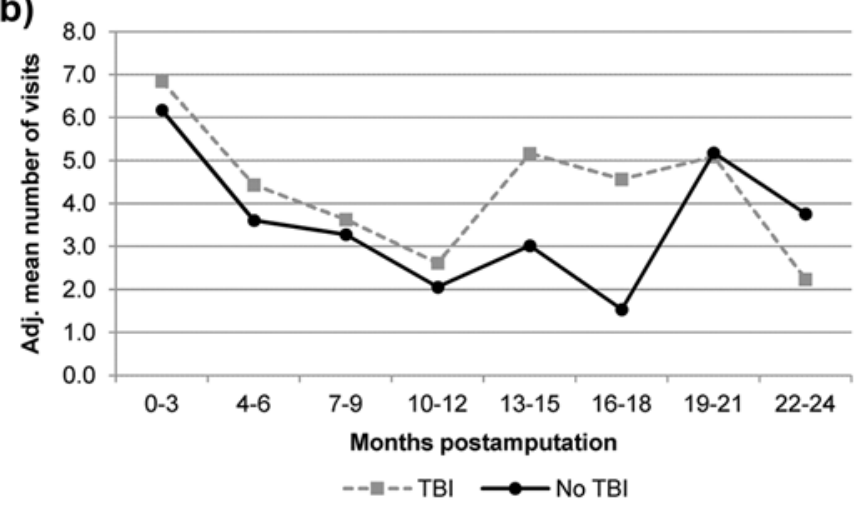

(c)

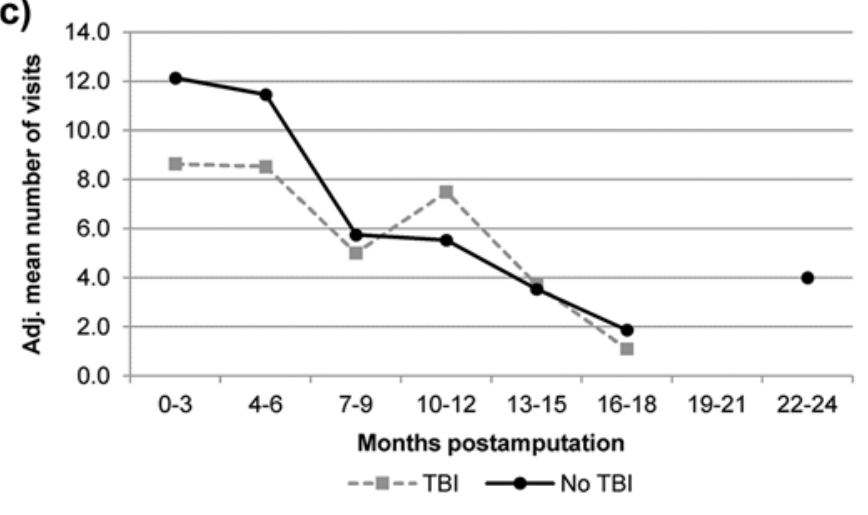

Figure.

Adjusted (adj.) mean number of (a) physical therapy, (b) occupational therapy, and (c) prosthetic training outpatient visits by traumatic brain injury (TBI) status during 3 mo intervals during follow-up, 2001-2006 $(n=222)$. Means are adjusted for Injury Severity Score and amputation location (upper limb, lower limb, or both) using parameter estimates obtained from Poisson regression models.

When we adjusted for ISS and amputation location, servicemembers with TBI had twice the odds $(\mathrm{OR}=2.0$, $95 \%$ CI $=1.0-4.1)$ of having five or more complications than servicemembers without TBI (Table 6). For individual complications, servicemembers with TBI had three times the odds of developing cellulitis (OR $=2.7,95 \%$ CI $=1.1-6.3)$, an infection or inflammatory process related to the prosthetic device $(\mathrm{OR}=3.1,95 \% \mathrm{CI}=1.3-$ 7.4), or a DVT and/or PE (OR $=2.3,95 \% \mathrm{CI}=1.0-5.1)$ than servicemembers without TBI.

\section{DISCUSSION}

To our knowledge, this is one of the first studies to report the effect of TBI on military discharge status and medical and rehabilitative care among U.S. servicemembers who had a combat-related major limb amputation in OIF/OEF. According to our findings, servicemembers who had a limb amputation and who sustained a TBI were more likely to have a higher usage of combined medical, physical therapy, and occupational therapy services than those without a TBI diagnosis. This finding remained significant after controlling for potential confounding variables between servicemembers with and without TBI, such as anatomical location of injury and ISS. TBI was also significantly associated with (1) a more severe bilateral lower-limb or a unilateral transfemoral amputation; (2) a higher ISS; (3) a greater number of other injuries; and (4) more postinjury complications, especially cellulitis, infection due to a device, or DVT and/or PE.

\section{Frequency of Traumatic Brain Injury in Servicemembers with Combat Amputations}

Traumatic limb loss involves many short- and longterm physical and psychosocial issues, including those related to heterotopic ossification, recurrent infection, prosthetic donning, ambulation, activities of daily living, depression, posttraumatic stress disorder, and return to duty [21,34-35]. A consequence unique to this population is increased risk of TBI caused by blast injury from land mines, rocket-propelled grenades, bombs, artillery, and IEDs [21]. We found that 23.3 percent of the servicemembers who had a traumatic amputation also incurred a TBI. MacGregor et al. reported a TBI prevalence of approximately 16 percent in a sample of U.S. combatants injured during 2004 and 2005 [36]. Our present study and MacGregor et al.'s results are based on diagnostic codes from clinical encounters. Thus, they may underestimate TBI rates because they exclude patients who do not seek 
Table 6.

Postinjury complications for servicemembers by traumatic brain injury (TBI) status in Operation Iraqi Freedom/Operation Enduring Freedom, 2001-2006 $(n=222)$.

\begin{tabular}{|c|c|c|c|c|}
\hline Complication & $\begin{array}{c}\text { TBI } \\
(n=56), n(\%)\end{array}$ & $\begin{array}{c}\text { No TBI } \\
(n=166), n(\%)\end{array}$ & $\begin{array}{c}\text { OR } \\
(95 \% \mathrm{CI})\end{array}$ & $\begin{array}{c}\text { AOR }^{*} \\
(95 \% \mathrm{CI})\end{array}$ \\
\hline \multicolumn{5}{|l|}{ No. } \\
\hline$\geq 5$ & $23(41.1)$ & $35(21.1)$ & $2.6(1.4-5.0)$ & $2.0(1.0-4.1)$ \\
\hline \multicolumn{5}{|l|}{ Type } \\
\hline Cellulitis & $12(21.4)$ & $19(11.5)$ & $2.1(0.9-4.7)$ & $2.7(1.1-6.3)$ \\
\hline Nonhealing Wound & $3(5.4)$ & $6(3.6)$ & $1.5(0.4-6.2)$ & $2.7(0.6-12.0)$ \\
\hline Pneumonia & $13(23.2)$ & $16(9.6)$ & $2.8(1.3-6.3)$ & $1.6(0.6-4.0)$ \\
\hline DVT and/or PE & $17(30.4)$ & $20(12.1)$ & $3.2(1.5-6.6)$ & $2.3(1.0-5.1)$ \\
\hline Bacterial Infection & $25(44.6)$ & 58 (34.9) & $1.5(0.8-2.8)$ & $1.4(0.7-2.7)$ \\
\hline Septicemia & 10 (17.9) & $12(7.2)$ & $2.8(1.1-6.9)$ & $1.5(0.5-4.1)$ \\
\hline Heterotopic Ossification & $21(37.5)$ & 37 (22.3) & $2.1(1.1-4.0)$ & $1.5(0.7-3.0)$ \\
\hline Chronic Infection (residual limb) & $10(17.9)$ & $29(17.5)$ & $1.0(0.5-2.3)$ & $1.4(0.7-3.0)$ \\
\hline
\end{tabular}

${ }^{*}$ ORs are adjusted for Injury Severity Score and amputation location (upper limb, lower limb, or both).

AOR = adjusted odds ratio, $\mathrm{CI}$ = confidence interval, DVT = deep vein thrombosis, OR = odds ratio, $\mathrm{PE}$ = pulmonary embolism.

medical care for these types of injuries. The potential underestimation of TBI might also be because the signs and symptoms typical of mild TBI were not salient enough to be diagnosed and identified relative to the trauma of the limb loss. Among a sample of mostly Army patients with blast injuries, a previous study reported TBI diagnoses for 59 percent of OIF/OEF warfighters admitted to Walter Reed Army Medical Center during 2003 and 2004 [37].

\section{Anatomical Location of Amputation by Traumatic Brain Injury Status}

Servicemembers with TBI were more likely to have a bilateral lower-limb or transfemoral amputation than servicemembers without TBI. These findings may be because servicemembers who incurred a TBI and traumatic amputation were more likely to have incurred their injuries as a result of a blast injury, particularly mine explosion, than any other mechanism of injury. Mine explosion mechanisms are usually from the ground up, which may cause more traumatic lower-limb injuries. The explosion's intense blast wave, by itself, may cause the TBI occurrence [38].

\section{Severity of Injury}

Recent literature emphasizes polytraumatic injuries among combat causalities returning from OIF/OEF [39]. Several of our findings suggest that servicemembers who had a greater number of injuries and/or a higher ISS had a greater likelihood of incurring a TBI. Our results suggest that multiple injuries may be an indicator for possible TBI.

\section{Traumatic Brain Injury and Discharge to Civilian Status}

We found that servicemembers who remained in military service after their amputation were more likely to be senior enlisted personnel or officers. Because the pay grade is higher and duties required are less physically demanding in general, these factors may contribute to staying in the military regardless of amputation. Stinner et al. reported a service retention rate of approximately 16 percent among servicemembers with recent combat amputation [40], which is substantially lower than the 40.7 percent we observed. Our findings may overestimate service retention in the present sample because of administrative delays during medical evaluation boards and completing the patient's 
discharge or methodological differences since we started data collection from time of injury up to 2 yr postamputation rather than 2 or more years after the incident. Pasquina et al. also indicated that the discharge process was among the least satisfactory aspects of postinjury care, which could affect retention rates [41].

\section{Medical and Rehabilitative Visits by Traumatic Brain Injury Status}

The effect of TBI among servicemembers with a combat-related major limb traumatic amputation was most apparent when looking at their medical and rehabilitative use. After adjusting for ISS and amputation location, servicemembers with a recorded TBI, on average, required a significantly greater number of physical therapy, occupational therapy, and combined medical and rehabilitative visits over the 2 yr follow-up period. For outpatient visits, we observed a relatively high use of outpatient physical therapy, occupational therapy, and prosthetic training services soon after the injury, which is similar to those reported by others $[21,34,42-43]$. Throughout much of the 2 yr follow-up period, the mean number of occupational therapy visits remained higher for servicemembers with TBI relative to those without TBI.

In summary, these findings suggest that servicemembers with TBI and a lower-limb amputation may be more likely to require additional medical and rehabilitative services over a longer time period, especially occupational therapy. The reasons for the larger amount of services needed toward the end of the $2 \mathrm{yr}$ follow-up period for those with TBI are not clear but may be related to symptoms associated with TBI, including balance deficits or disorders and other neurologic sequelae [44]. This may be especially true for the greater difference in occupational visits toward the end of the follow-up period since occupational therapists typically are in charge of cognitive and functional skills in the military.

\section{Postinjury Complications by Traumatic Brain Injury Status}

After adjusting for overall ISS and amputation location, servicemembers with TBI were significantly more likely to have had more postinjury complications, especially cellulitis, infection or inflammatory process related to the prosthetic device, or DVT and/or PE. These conditions are usually related to the wound type, wound care management, and prosthetic training processes. It may be that those with TBI had an amputation with a graft or wound that was less likely to heal, or the servicemem- ber's inability to properly take care of his or her skin wound condition and/or ensure proper prosthetic device cleanliness. These complications should be considered when evaluating and planning short- and long-term rehabilitative care for a servicemember with a TBI.

\section{Strengths and Limitations}

To our knowledge, we are the first to report the effect that TBI may have on discharge to civilian status and medical and rehabilitative care among U.S. servicemembers who had a traumatic amputation in OIF/OEF. The longitudinal design allowed us to assess service status and medical and rehabilitative use over a $2 \mathrm{yr}$ follow-up period. Additionally, the sample size was large enough to enable us to analyze associations between TBI and important amputation and medical and/or rehabilitative care issues concurrently, while adjusting for injury severity and amputation location.

Limitations of our study should be noted. First, while we had data regarding the amount of services used, we did not have data that allowed us to specifically determine the proportions of specific functional or skill levels achieved. Thus, even at the $2 \mathrm{yr}$ follow-up we were unsure whether TBI affected the servicemember's ability to achieve activity of daily living functional skills (i.e., bed mobility, transfers, dressing, toileting, or residential and/or community ambulation [with or without assistive device and with or without prosthetic device]), specific skills (e.g., functionally independent with wound care and prosthetic use), or more global areas (return to service or other occupation). Second, the CHAMPS database does not collect data regarding medical and rehabilitation service usage for servicemembers who have been discharged from Active Duty military service. Approximately 60 percent of our sample with major limb amputation were discharged from Active Duty military service; therefore, some bias may have been introduced into findings of our analyses of those in the $2 \mathrm{yr}$ follow-up period. Third, the use of ICD-9 code 310.2 to classify TBI may have led to an overestimation of the frequency of TBI because of potential inclusion of concussions predating the amputation event, thus reducing generalizability of our finding. Therefore, the potential for the overattribution of TBI may have existed. Conversely, a certain percentage of TBIs may not have been reported for reasons such as lack of knowledge of associated symptoms [45] or servicemember's strong desire to remain with the unit, concerns for delaying personal leave because of required medical care, and less commonly, commander's request [46]. In this case, the finding that 23.3 percent of 
the servicemembers reporting an amputation also reported a TBI supports the need for further research into the special needs of this population with both TBI and amputation. Finally, although this study attempted to account for differences in injury severity using ISS, this scale may not have been a sensitive measure of TBI severity. Though we only report data from a 2 yr follow-up period, it would be beneficial to follow this subject group for a longer time period since rehabilitative care and ability to return to normal activities of daily living can take several years.

\section{CONCLUSIONS}

Little knowledge exists regarding the effect of TBI among U.S. servicemembers with combat-related major limb amputation, especially on the short- and long-term use of medical and rehabilitative services. In light of this, we have indicated that servicemembers with TBI are more likely to require frequent and prolonged rehabilitation. While this finding allows those in administrative positions to plan for the sufficient allocation of financial and other resources for this group of patients, it suggests that those providing rehabilitative and prosthetic training should screen for history of TBI when developing a care plan. Based on our results, servicemembers who had a greater number of injuries and/or a higher ISS had a greater likelihood of incurring a TBI. Therefore, we suggest that servicemembers with multiple injuries be screened for possible TBI.

Future studies should be prospectively designed to longitudinally examine the patterns and functional outcomes for this growing group of individuals in short- and long-term follow-up studies. We recommend that future studies gather more detailed information regarding TBI, particularly indicators of severity, including the presence of loss of consciousness, posttraumatic amnesia, and altered mental status. Assessing these factors may allow better classification of TBI as mild, moderate, or severe. However, challenges in classification of TBI in this population still exist, including factors such as altered mental status caused by medication or induced coma during initial care. Additionally, studies are needed to assess whether cognitive impairment related to TBI plays a significant role in increased medical and rehabilitative usage among servicemembers with limb loss. Finally, studies designed to determine the best techniques to increase the effectiveness of rehabilitative efforts are warranted.

\section{ACKNOWLEDGMENTS}

\section{Author Contributions:}

Study concept and design: M. J. Rauh, H. J. Aralis.

Acquisition of data: M. R. Galarneau.

Analysis and interpretation of data: H. J. Aralis, M. J. Rauh, T. Melcer, C. A. Macera, J. Bartlett, P. Sessoms, M. R. Galarneau.

Drafting of manuscript: M. J. Rauh, H. J. Aralis.

Critical revision of manuscript for important intellectual content:

M. J. Rauh, H. J. Aralis, T. Melcer, C. A. Macera, J. Bartlett,

P. Sessoms, M. R. Galarneau.

Statistical analysis: H. J. Aralis.

Financial Disclosures: The authors have declared that no competing interests exist.

Funding/Support: This material was based on work supported by the Wounded, Ill, and Injured/Traumatic Brain Injury program of the U.S. Navy Bureau of Medicine and Surgery (DOD work unit no. 60818).

Institutional Review: The Naval Health Research Center Institutional Review Board approved this study protocol (NHRC.2009.0022). This research has been conducted in compliance with all applicable Federal regulations governing the protection of human subjects.

Participant Follow-Up: The authors do not plan to notify study subjects of the publication of this article because this study is defined as minimal risk to subjects. Existing data were accessed for a large population of military servicemembers.

Disclaimer: The views expressed in this article are those of the authors and do not reflect the official policy or position of the Department of the Navy, DOD, or U.S. Government.

\section{REFERENCES}

1. Fischer H. United States military casualty statistics: Operation Iraqi Freedom, Operation New Dawn, and Operation Enduring Freedom [Internet]. Washington (DC): Department of Defense; 2013 [updated 2013 Jan 18; cited 2008 Sep 9]. Available from: http://www.defenselink.mil/news/casualty.pdf

2. Pasquina PF. Optimizing care for combat amputees: Experiences at Walter Reed Army Medical Center. J Rehabil Res Dev. 2004;41(3B):vii-xii. [PMID:15543454] http://dx.doi.org/10.1682/JRRD.2004.05.0051

3. Cansever A, Uzun O, Yildiz C, Ates A, Atesalp AS. Depression in men with traumatic lower part amputation: a comparison to men with surgical lower part amputation. Mil Med. 2003;168(2):106-9. [PMID:12636136]

4. Chwalisz K, Vaux A. Social support and adjustment to disability. In: Frank RG, Elliot TR, editors. Handbook of rehabilitation psychology. Washington (DC): American Psychological Association; 2000. p. 537-52.

5. Cole PA, Bhandari M. What's new in orthopaedic trauma. J Bone Joint Surg Am. 2005;87(12):2823-38. [PMID:16322635] http://dx.doi.org/10.2106/JBJS.E.01068 
6. Curley MD, Walsh JM, Triplett RG. Some adjustment indices of oral-maxillofacial war casualties, limb amputees, and noninjured veterans. Mil Med. 1982;147(7):572-74. [PMID:6815575]

7. Crichlow RJ, Andres PL, Morrison SM, Haley SM, Vrahas MS. Depression in orthopaedic trauma patients. Prevalence and severity. J Bone Joint Surg Am. 2006;88(9):1927-33. [PMID:16951107] http://dx.doi.org/10.2106/JBJS.D.02604

8. Gunawardena NS, Seneviratne RA, Athauda T. Functional outcomes of unilateral lower limb amputee soldiers in two districts of Sri Lanka. Mil Med. 2006;171(4):283-87. [PMID:16673739]

9. Hebela N, Smith DG, Keenan MA. What's new in orthopaedic rehabilitation. J Bone Joint Surg Am. 2004;86-A(11): 2577-81. [PMID:15523043]

10. Heineman AW. Functional status and quality of life measures. In: Frank RG, Elliot TR, editors. Handbook of rehabilitation psychology. Washington (DC): American Psychological Association; 2000. p. 261-86.

11. Hoaglund FT, Jergesen HE, Wilson L, Lamoreux LW, Roberts R. Evaluation of problems and needs of veteran lowerlimb amputees in the San Francisco Bay Area during the period 1977-1980. J Rehabil Res Dev. 1983;20(1):57-71. [PMID:6887067]

12. Kishbaugh D, Dillingham TR, Howard RS, Sinnott MW, Belandres PV. Amputee soldiers and their return to active duty. Mil Med. 1995;160(2):82-84. [PMID:7783923]

13. Lin DL, Kirk KL, Murphy KP, McHale KA, Doukas WC. Evaluation of orthopaedic injuries in Operation Enduring Freedom. J Orthop Trauma. 2004;18(8 Suppl):S48-53. [PMID:15472566] http://dx.doi.org/10.1097/00005131-200409001-00008

14. McCarthy ML, MacKenzie EJ, Edwin D, Bosse MJ, Castillo RC, Starr A; LEAP study group. Psychological distress associated with severe lower-limb injury. J Bone Joint Surg Am. 2003;85-A(9):1689-97. [PMID:12954826]

15. Rybarczyk B, Szymanski L, Nicholas JJ. Limb amputation. In: Frank RG, Elliot TR, editors. Handbook of rehabilitation psychology. Washington (DC): American Psychological Association; 2000. p. 29-38.

16. Starr AJ, Smith WR, Frawley WH, Borer DS, Morgan SJ, Reinert CM, Mendoza-Welch M. Symptoms of posttraumatic stress disorder after orthopaedic trauma. J Bone Joint Surg Am. 2004;86-A(6):1115-21. [PMID:15173282]

17. Javemick MA, Doukas WC. Process of care for battle casualties at Walter Reed Army Medical Center: Part I. Orthopedic surgery service. Mil Med. 2006;171(3):200-202. [PMID:16602514]

18. Pasquina PF, Fitzpatrick K. The Walter Reed experience: current issues in the care of the traumatic amputee. J Prosthet Orthot. 2006;18:119-22.
19. Pasquina PF, Gambel J, Foster LS, Kim A, Doukas WC. Process of care for battle casualties at the Walter Reed Army Medical Center: Part III. Physical medicine and rehabilitation service. Mil Med. 2006;171(3):206-8.

[PMID:16602516]

20. Springer BA, Doukas WC. Process of care for battle casualties at Walter Reed Army Medical Center: Part II. Physical therapy service. Mil Med. 2006;171(3):203-5.

[PMID:16602515]

21. Gajewski D, Granville R. The United States Armed Forces Amputee Patient Care Program. J Am Acad Orthop Surg. 2006;14(10 Spec No.):S183-87. [PMID:17003196]

22. Whitney MR. Revolutionizing prosthetics. Mil Med Tech. 2005;9(6):38-41.

23. Armed Forces Health Surveillance Center. Amputations of lower and upper extremities, US Armed Forces, 1990-2004. MSMR. 2005;11:2-6.

24. Galarneau MR, Woodruff SI, Dye JL, Mohrle CR, Wade AL. Traumatic brain injury during Operation Iraqi Freedom: findings from the United States Navy-Marine Corps Combat Trauma Registry. J Neurosurg. 2008;108(5):950-57. [PMID:18447712] http://dx.doi.org/10.3171/JNS/2008/108/5/0950

25. Blumentritt S, Schmalz T, Jarasch R. The safety of C-leg: biomechanical tests. J Prosthet Orthot. 2009;21:2-15.

26. Hafner BJ, Willingham LL, Buell NC, Allyn KJ, Smith DG. Evaluation of function, performance, and preference as transfemoral amputees transition from mechanical to microprocessor control of the prosthetic knee. Arch Phys Med Rehabil. 2007;88(2):207-17. [PMID:17270519] http://dx.doi.org/10.1016/j.apmr.2006.10.030

27. Stone LR, Keenan MA, Shin DY. Acquired limb loss in patients with traumatic brain injury. Am J Phys Med Rehabil. 1990;69(3):135-39. [PMID:2363904] http://dx.doi.org/10.1097/00002060-199006000-00007

28. Galarneau MR, Hancock WC, Konoske P, Melcer T, Vickers RR, Walker GJ, Zouris JM. The Navy-Marine Corps Combat Trauma Registry. Mil Med. 2006;171(8):691-97. [PMID:16933807]

29. Gunderson EK, Garland CF, Miller MR, Gorham ED. Career History Archival Medical and Personnel System. Mil Med. 2005;170(2):172-75. [PMID:15782842]

30. Barell V, Aharonson-Daniel L, Fingerhut LA, Mackenzie EJ, Ziv A, Boyko V, Abargel A, Avitzour M, Heruti R. An introduction to the Barell body region by nature of injury diagnosis matrix. Inj Prev. 2002;8(2):91-96. [PMID:12120842] http://dx.doi.org/10.1136/ip.8.2.91

31. Carroll LJ, Cassidy JD, Peloso PM, Borg J, von Holst H, Holm L, Paniak C, Pépin M; WHO Collaborating Centre Task Force on Mild Traumatic Brain Injury. Prognosis for mild traumatic brain injury: results of the WHO Collaborating Centre Task Force on Mild Traumatic Brain Injury. J Rehabil 
Med. 2004;(43 Suppl):84-105. [PMID:15083873]

http://dx.doi.org/10.1080/16501960410023859

32. Copes WS, Champion HR, Sacco WJ, Lawnick MM, Keast SL, Bain LW. The Injury Severity Score revisited. J Trauma. 1988;28(1):69-77. [PMID:3123707] http://dx.doi.org/10.1097/00005373-198801000-00010

33. Demetriades D, Martin M, Salim A, Rhee P, Brown C, Doucet J, Chan L. Relationship between American College of Surgeons trauma center designation and mortality in patients with severe trauma (injury severity score $>15$ ). J Am Coll Surg. 2006;202(2):212-15, quiz A45. [PMID:16427544] http://dx.doi.org/10.1016/j.jamcollsurg.2005.09.027

34. Melcer T, Walker GJ, Galarneau MR, Belnap B, Konoske P. Midterm health and personnel outcomes of recent combat amputees. Mil Med. 2010;175(3):147-54. [PMID:20358702]

35. Potter BK, Scoville CR. Amputation is not isolated: an overview of the US Army Amputee Patient Care Program and associated amputee injuries. J Am Acad Orthop Surg. 2006;14(10 Spec No.):S188-90. [PMID:17003197]

36. MacGregor AJ, Shaffer RA, Dougherty AL, Galarneau MR, Raman R, Baker DG, Lindsay SP, Golomb BA, Corson KS. Prevalence and psychological correlates of traumatic brain injury in Operation Iraqi Freedom. J Head Trauma Rehabil. 2010;25(1):1-8. [PMID:20051901] http://dx.doi.org/10.1097/HTR.0b013e3181c2993d

37. Okie S. Traumatic brain injury in the war zone. N Engl J Med. 2005;352(20):2043-47. [PMID:15901856] http://dx.doi.org/10.1056/NEJMp058102

38. Covey DC, Aaron RK, Born CT, Calhoun JH, Einhorn TA, Hayda RA, Levin LS, Mazurek MT, Murray CK, Powell ET, Schwarz EM, Wenke JC. Orthopaedic war injuries: from combat casualty care to definitive treatment: a current review of clinical advances, basic science, and research opportunities. Instr Course Lect. 2008;57:65-86. [PMID:18399571]

39. Uomoto JM, Williams RM. Post-acute polytrauma rehabilitation and integrated care of returning veterans: toward a holistic approach. Rehabil Psychol. 2009;54(3):259-69. [PMID:19702424] http://dx.doi.org/10.1037/a0016907

40. Stinner DJ, Burns TC, Kirk KL, Ficke JR. Return to duty rate of amputee soldiers in the current conflicts in Afghanistan and Iraq. J Trauma. 2010;68(6):1476-79. [PMID:20068483] http://dx.doi.org/10.1097/TA.0b013e3181bb9a6c
41. Pasquina PF, Tsao JW, Collins DM, Chan BL, Charrow A, Karmarkar AM, Cooper RA. Quality of medical care provided to service members with combat-related limb amputations: report of patient satisfaction. J Rehabil Res Dev. 2008;45(7):953-60. [PMID:19165685] http://dx.doi.org/10.1682/JRRD.2007.10.0163

42. Pasquina PF, Bryant PR, Huang ME, Roberts TL, Nelson VS, Flood KM. Advances in amputee care. Arch Phys Med Rehabil. 2006;87(3 Suppl 1):S34-43, quiz S44-45. [PMID:16500191] http://dx.doi.org/10.1016/j.apmr.2005.11.026

43. Smurr LM, Gulick K, Yancosek K, Ganz O. Managing the upper extremity amputee: a protocol for success. J Hand Ther. 2008;21(2):160-75, quiz 176. [PMID:18436138] http://dx.doi.org/10.1197/j.jht.2007.09.006

44. Lew HL, Poole JH, Vanderploeg RD, Goodrich GL, Dekelboum S, Guillory SB, Sigford B, Cifu DX. Program development and defining characteristics of returning military in a VA Polytrauma Network Site. J Rehabil Res Dev. 2007; 44(7):1027-34. [PMID:18075959] http://dx.doi.org/10.1682/JRRD.2007.05.0073

45. Belanger HG, Scott SG, Scholten J, Curtiss G, Vanderploeg RD. Utility of mechanism-of-injury-based assessment and treatment: Blast Injury Program case illustration. J Rehabil Res Dev. 2005;42(4):403-12. [PMID:16320137] http://dx.doi.org/10.1682/JRRD.2004.08.0095

46. Drake AI, Meyer KS, Cessante LM, Cheung CR, Cullen MA, McDonald EC, Holland MC. Routine TBI screening following combat deployments. NeuroRehabilitation. 2010; 26(3):183-89. [PMID:20448308]

Submitted for publication November 4, 2011. Accepted in revised form June 26, 2012.

This article and any supplementary material should be cited as follows:

Rauh MJ, Aralis HJ, Melcer T, Macera CA, Sessoms P, Bartlett J, Galarneau MR. Effect of traumatic brain injury among U.S. servicemembers with amputation. J Rehabil Res Dev. 2013;50(2):161-72. http://dx.doi.org/10.1682/JRRD.2011.11.0212

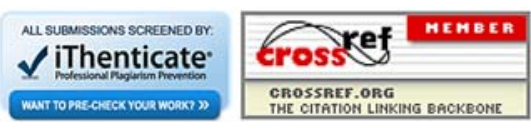

